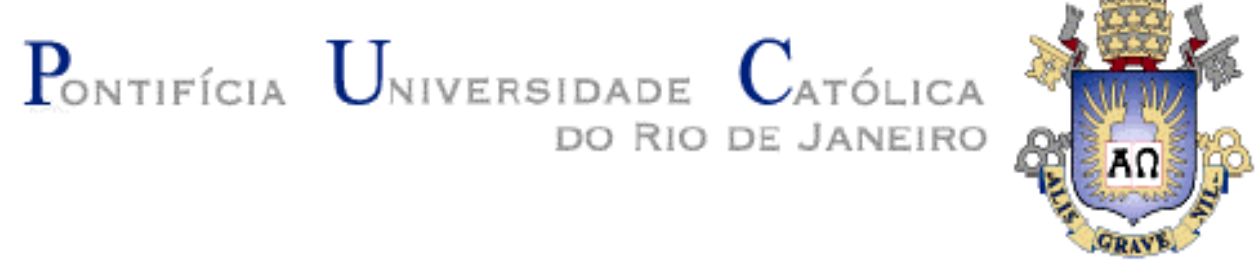

Mariana Nazaré Livramento

\title{
UM ESTUDO SOBRE OS VALORES NO CONSUMO DE PRODUTOS DE BELEZA POR MULHERES DE BAIXA \\ RENDA
}

\section{Dissertação de Mestrado}

Dissertação apresentada ao Programa de Pósgraduação em Administração de Empresas da PUCRio como requisito parcial para obtenção do título de Mestre em Administração de Empresas.

Orientador: Prof. Luis Fernando Hor-Meyll Alvares

Rio de Janeiro

Agosto de 2010 


\title{
Mariana Nazaré Livramento
}

\section{Um estudo sobre os valores no consumo de produtos de beleza por mulheres de baixa renda}

\begin{abstract}
Dissertação apresentada como requisito parcial para obtenção do grau de Mestre pelo Programa de Pósgraduação em Administração de Empresas da PUC-Rio. Aprovada pela Comissão Examinadora abaixo assinada.
\end{abstract}

Prof. Luis Fernando Hor-Meyll Alvares

Orientador(a)

Departamento de Administração - PUC-Rio

Profa. Angela Maria Cavalcanti da Rocha Departamento de Administração - PUC-Rio

Prof. José Luis Felicio dos Santos de Carvalho UFRJ

Profa. Mônica Herz

Vice-Decana de Pós-Graduação do CCS

Rio de Janeiro, 27 de agosto de 2010 
Todos os direitos reservados. É proibida a reprodução total ou parcial do trabalho sem autorização da universidade, da autora e do orientador.

\section{Mariana Nazaré Livramento}

Graduou-se em Farmácia na UFRJ (Universidade Federal do Rio de Janeiro) em 2004.

Ficha catalográfica

Livramento, Mariana Nazaré

Um estudo sobre os valores no consumo de produtos de beleza por mulheres de baixa renda / Mariana Nazaré Livramento ; orientador: Luis Fernando Hor-Meyll Alvares. - 2010.

$68 \mathrm{f}$. : il. ; $30 \mathrm{~cm}$

Dissertação (mestrado)-Pontifícia Universidade Católica do Rio de Janeiro, Departamento de Administração, 2010. Inclui bibliografia

1. Administração - Teses. 2. Beleza. 3. Produtos de beleza. 4. Mulheres de baixa renda e valores I. Alvares, Luis Fernando Hor-Meyll. II. Pontifícia Universidade Católica do Rio de Janeiro. Departamento de Administração. III. Título. 


\section{Agradecimentos}

A Deus, por sempre me iluminar e permitir que meus sonhos se realizem.

Aos meus pais, Luiz Carlos e Suely, e meu irmão Gustavo, pela dedicação e ensinamento, e por serem meus exemplos de vida. À Julie, pela companhia.

À minha família e amigos, por me apoiarem e me escutarem nos momentos mais difíceis.

Ao Leonardo, por ser meu grande incentivador a fazer o mestrado e por estar sempre ao meu lado.

Às minhas companheiras da Dermatus, pelo suporte dado em toda a minha carreira e por me apoiarem nos momentos mais angustiantes dessa caminhada.

Aos amigos da turma do mestrado, em especial Carol, Cynthia, Gabi, Labruna e Suzane.

Ao meu orientador, Professor Luis Fernando Hor-Meyll, pelas excelentes aulas e ensinamentos, fundamentais para que alcançasse meu objetivo.

Às mulheres entrevistadas que gentilmente participaram dessa pesquisa.

A todos os professores do Mestrado em Administração da Escola de Negócios da PUC - Rio pela qualidade de ensino.

Aos funcionários da PUC - Rio, Teresa, Fábio e Mônica, pela competência e por estarem sempre prontos a nos ajudar.

Aos professores Angela da Rocha da PUC-Rio e José Carvalho da UFRJ pela presença na banca e que, com certeza, irão contribuir para a qualidade do trabalho. 


\section{Resumo}

Livramento, Mariana Nazaré; Hor-Meyll, Luis Fernando. Um estudo sobre os valores no consumo de produtos de beleza por mulheres de baixa renda. Rio de Janeiro, 2010. 68p. Dissertação de Mestrado - Departamento de Administração, Pontifícia Universidade Católica do Rio de Janeiro.

O mercado de baixa renda tem apresentado um significativo crescimento no seu potencial de consumo. No entanto, o restrito orçamento familiar deste mercado ainda limita o consumo de certos produtos. E mesmo convivendo com essa limitação financeira, muitas mulheres deste grupo consomem produtos que podem ser considerados supérfluos, como produtos de beleza. O objetivo desta dissertação é identificar os valores que levam as mulheres de baixa renda a consumir produtos de beleza. Conduziu-se um estudo exploratório, baseado em entrevistas em profundidade com 17 mulheres. A interpretação das entrevistas, realizada com as técnicas laddering e grupo de focus e com análise de conteúdo, sugere que mulheres de baixa renda, ao comprarem produtos de beleza buscam reconhecimento social, serem respeitadas como indivíduos e, principalmente, auto-estima.

\section{Palavras-chave}

Beleza; produtos de beleza; mulheres de baixa renda; valores. 


\section{Abstract}

Livramento, Mariana Nazaré; Hor-Meyll, Luis Fernando (Advisor). A study about values on beauty products by low income women. Rio de Janeiro, 2010. 68p. MSc. Dissertation - Departamento de Administração, Pontifícia Universidade Católica do Rio de Janeiro.

The low-income market has shown a significant growth in its consumption potential. However, the limited family budget in this market have limited consumption of certain products. And even living with these financial constraints, many women in this group consume products that can be considered superfluous, as beauty products. The objective of this dissertation is to identify the values that takes low-income women to consume beauty products. It has conducted an exploratory study, based on interviews with 17 women. The interpretation of the interviews held with the laddering technique, focus group and content analysis, suggests that low-income women into buying beauty products seek social recognition, to be respected as individuals, and especially self-esteem.

\section{Keywords}

Beauty; beauty products; low income women; values. 


\section{Sumário}

1. Introdução 12

1.1. Objetivo do estudo 12

1.2. Relevância do estudo 13

1.3. Delimitação do estudo 14

1.4. Organização da dissertação 15

2. Revisão da literatura 16

2.1. Beleza 16

2.1.1. A mulher e a beleza 16

2.1.2. A busca pelo padrão estético 17

2.1.3. Beleza e consumo 19

2.2. As mulheres de baixa renda $\quad 21$

2.2.1. As restrições financeiras das mulheres de baixa renda 23

2.2.2. A busca pela beleza nas camadas populares 24

2.3. Valores $\quad 24$

2.4. A cadeia meios-fim $\quad 27$

2.4.1. Atributos 30

2.4.2. Conseqüências 31

3. Método 33

3.1. Coleta de dados 35

3.2. Limitações do método 36

4. Análise das entrevistas 38

4.1. Análise de conteúdo 38

4.2. Matriz de implicação $\quad 41$

4.3. Mapa hierárquico de valor $\quad 42$

4.4. Orientações de percepções dominantes 44

5. Discussão dos resultados $\quad 47$

5.1. Auto-estima 47

5.2. Ser respeitada $\quad 50$

5.3. A relação preço $x$ qualidade 51

5.4. A mulher de baixa renda e as marcas de produtos de beleza 52

5.5. A mulher de baixa renda e os cabelos 53

6. Conclusões 56

6.1. Sugestões para pesquisas futuras 58

7. Referências bibliográficas 59 
8. Anexos

8.1. Anexo I: Tabela de ladders

65

8.2. Anexo II: Matriz de Implicação

66

8.3. Anexo III: Matrizes individuais das cadeias dominantes 


\section{Lista de figuras}

Figura 1: Modelo de Vinson, Scott e Lamont 28

Figura 2: Modelo de cadeia meios-fim $\quad 30$

Figura 3: Mapa hierárquico de valor 43 


\section{Lista de quadros}

Quadro 1: Tipos de valores na escala de Rokeach 25

Quadro 2: Modelo de cadeia meios-fim de Howard 28

Quadro 3: Exemplo do modelo de cadeia de benefícios

de Young e Feigin 


\section{Lista de tabelas}

Tabela 1: Perfil das entrevistadas $\quad 36$

Tabela 2: Sumário de códigos 38

Tabela 3: Resumo das relações diretas e indiretas
de cada elemento 